\title{
Progress in the Development of Vision Prostheses
}

\author{
Mario Matthaei $^{\mathrm{a}}$ Oliver Zeitz ${ }^{\mathrm{a}}$ Matthias Keserü $^{\mathrm{a}}$ Lars Wagenfeld $^{\mathrm{a}}$ \\ Ralf Hornig $^{b}$ Nils Post $^{b}$ Gisbert Richard ${ }^{a}$ \\ ${ }^{a}$ Klinik und Poliklinik für Augenheilkunde, Universitätsklinikum Hamburg-Eppendorf, Hamburg, and \\ bIMI Intelligent Medical Implants GmbH, Bonn, Germany
}

\section{Key Words}

Retina $\cdot$ Visual prosthesis $\cdot$ Electrophysiology

\begin{abstract}
Degenerative retinal diseases like retinitis pigmentosa and age-related macular degeneration are among the most common causes of blindness worldwide. Electronic visual prostheses represent a potential therapeutic option of increasing importance in otherwise incurably impaired patients. Based on extensive animal experiments, several devices are now being tested in clinical trials. According to the placement of the electrodes, possible stimulation sites are located subretinally, epiretinally, along the optic nerve or cortically. Anatomical, physiological and pathophysiological aspects must be considered in development and clinical application. To provide an appropriate retinal substitute, the optimal integration and adaptation of the prosthesis into the highly complex system of the visual pathway is important. This article aims to summarize the relevant studies and provides an overview of the current status of developments and challenges that still need to be mastered.
\end{abstract}

Copyright ๑ 2011 S. Karger AG, Base
(C) 2011 S. Karger AG, Basel 0030-3755/11/2254-0187\$38.00/0

Fax +4161306 1234 E-Mail karger@karger.ch www.karger.com

\section{Introduction}

Infectious diseases and cataract have been the leading causes of blindness, and are still a major issue in many countries worldwide with low medical standards. Since both diseases can now be sufficiently treated, degenerative retinal diseases have become the most prevalent cause of blindness in developed countries. In this group of patients, age-related macular degeneration is the most commonly found disorder. Preliminary stages affect up to $30 \%$ of the population over 70 years of age [1]. In younger age groups, hereditary retinal diseases are of particular importance. These are less frequent by far than age-related macular degeneration but severely affect quality of life. Despite considerable progress in the basic research into the pathogenesis of degenerative retinal diseases, therapeutic options are still limited. However, neuroprotective therapies or cell-based tissue reconstitution, like the application of stem cells, raise hope for future therapeutic approaches. The replacement of a degenerated retina by an electric stimulator might be an alternative to biological and pharmacological therapies. This idea is not new; the first reports on eliciting phosphenes by electric stimulation of the visual system date back to the 18th century [2]. 
The systematic development of an electronic retinal prosthesis was pushed forward by advances in microcomputer technology. Since the 1990s, different work groups have aimed at developing a market-ready device. This development is partly driven by the success of cochlea implants. Here we review the current progress of artificial sight and outline the problems during its development and clinical application.

\section{Integrational Options of a Visual Prosthesis into the Visual Pathway}

Light effects the decay of opsins in healthy photoreceptors. This marks the starting point of a signal cascade, which results in the closure of $\mathrm{Na}-\mathrm{Ca}$ channels, thus hyperpolarizing these cells. This is accompanied by a diminished neurotransmitter release. The on- and off-center amacrine cells and ganglion cells are depolarized, by the neurotransmitter glutamate, via the on- and off-center bipolar cells. The generated action potential leaves the eye through the axons of the ganglion cells, which form the optic nerve.

The visual system from the retina to the visual cortex is a complex interconnected system of 4 neurons, 3 of which are positioned within the retina. The system is characterized by convergence, meaning that more than 1 photoreceptor may be assigned to a single neuron and vice versa. The convergence of the signal already occurs within the retina. Multiple photoreceptors are integrated into receptive fields. There is a stringent visutopic order for these receptive fields within the course of the visual pathway, which is maintained until reaching the visual cortex. The topographical situation in the visual system is complicated as parts of the visual pathway cross each other and the position of their fibers is distorted.

Basically, the implantation of a visual prosthesis is imaginable at any position along the visual pathway. Potential implantation sites are highlighted in figure 1. A retinal perception of light caused by electrical stimulation (phosphene) may be evoked by 3 mechanisms: (1) by depolarization and action potential generation within the axons of ganglion cells, (2) by direct depolarization of the ganglion cells themselves and (3) by depolarization of upstream cells such as amacrine and bipolar cells [3].

In choosing the individual location for the prosthesis, anatomical and physiological preconditions as well as pathology and pathophysiology of the underlying visual impairment have to be considered. However, the func- tionality of the downstream neurons within the visual pathway plays a crucial role.

Retinal dystrophies primarily affect the photoreceptor layer. However, layers located further inside are also likely to be affected, presumably by transneuronal degeneration. For example, downstream cells degenerate due to the lack of stimulation by their upstream neurons. Nevertheless, morphometric analysis of eyes with a diagnosis of retinitis pigmentosa have shown that within the macular region, compared to healthy controls, $50-75 \%$ of ganglion cells are retained [4]. Rods, amacrine and horizontal cells, however, seem to undergo neurite sprouting, which further complicates the adjustment of a prosthesis $[5,6]$. In eyes with dry age-related macular degeneration, a good preservation of cells within the inner nuclear and the ganglion cell layer has been demonstrated [7].

Once received by photoreceptors, the signal is initially modulated within the retina. The subsequent signal sent out by the bipolar cells is no longer related to any order of a matrix of singular pixels but is complexly encoded. The situation is further complicated by the fact that within the fovea the inner retinal layers are displaced paracentrally. Thus, a stimulation of these cells by electrodes placed directly in a sub- or suprafoveolar position is almost impossible.

Because the photoreceptors are convergently interconnected with the downstream convergent bipolar and ganglion cells, the easiest way would be to place a prosthesis subretinally, from the point of physiological signal processing.

\section{Subretinal Implants}

From a surgical perspective, it is challenging to place an implant in a subretinal position. Apart from the complex accessibility of the subretinal space, the connection of the stimulator with additional components of the system, such as an energy source, is another major problem with a subretinal localization. In the 1990s, attempts were made to approach the difficulties of a transscleral connection by placing a silicon-based and light-powered device containing microelectrode-tipped microphotodiodes into the subretinal space $[8,9]$. The results from experiments in rabbits showed that potentials within the visual cortex could be generated by this system. The socalled artificial silicon retina implant was implanted into 6 patients and was well tolerated over the observation period of $1-1.5$ years up to 4.5 years postoperatively $[10,11]$. The authors report an improvement of sight. However, 
the efficacy of the artificial silicon retina has to be questioned since visual perceptions which can definitively be assigned to the implant only occur by stimulation of very large retinal areas [12]. This implies that, with this approach, the electrical charge released per area on exposure to light is not sufficient, and an adequate power supply is lacking. The authors suggested that positive effects of the implant on vision seen in the human experiments were potentially due to a neuroprotective effect of subliminal stimulation of the photoreceptors $[13,14]$. A combination of a subretinal photovoltaic implant and an extraocular amplifying unit for the received picture information has been proposed to deliver an improved efficiency of photovoltaic implants [15]. The amplification of the picture information occurs via a camera-monitor system that illuminates the implant with highly energetic infrared light. The given wavelength and the photodiodes are adjusted to each other. Possible thermal side effects of a chronic infrared radiation of the retina have so far not been investigated.

Another subretinal concept that has been developed over many years consists of photodiodes being energized by an extraocular wired energy source. The investigators have concentrated on testing its biocompatibility and ways to improve it [16]. Subretinal fluid is initially released as a response to this subretinal foreign body, disrupting the contact between retina and photoreceptors. To create sufficient contact, a silicone oil endotamponade is necessary. Nevertheless, in up to $50 \%$ of all experiments no cortical potentials could be recorded, presumably due to contact problems. After improving the system and additional development of film electrodes [17], the team inserted subretinal implants into several patients and was able to achieve visual perceptions in some cases, i.e. in scanning laser ophthalmoscope microperimetry and lately even in visual acuity determined by the Landolt $\mathrm{C}$ test $[18,19]$.

In a new subretinal approach followed by another German group, sclera-penetrating electrodes are pierced under the retina forming a matrix [20]. This technique simplifies the surgical procedure and is therefore termed 'minimally invasive' by its inventors. The concept is currently being tested in primates. The transscleral electrodes provide multiple small but permanent connections to the outside. Long-term side effects are not yet known. Furthermore, it has to be clarified whether the position of the electrodes is stable over a long-term course. Similarly to the subretinal approach described above, the electric contact in this system might be disturbed by exudation of subretinal fluid. Perforation of Bruch's mem- brane can also cause development of choroidal neovascularization.

It is doubtful whether, after replacement of photoreceptors with a subretinal implant, the signals will reach the ganglion cells following the normal pathway, since a photoreceptor degeneration also causes a degeneration of the inner retinal layers. Because of degenerations within the inner plexiform layer, the signal reaching the ganglion cells could be nonspecific. Therefore some research groups prefer a direct stimulation of ganglion cells by epiretinally localized stimulator electrodes. From a surgical point of view, standard methods of vitreoretinal surgery can be utilized [Keserü et al., unpubl. results] to a certain extent, and, compared to subretinal implantation, no retinal detachment has to be performed.

\section{Epiretinal Implants}

As early as the 1990s, it was reported that stimulation of the inner retinal layers may cause a light perception in blind patients with retinitis pigmentosa [21]. The authors determined that, using their platinum electrodes, charge densities of $160-3,200 \mu \mathrm{C} / \mathrm{cm}^{2}$ were required to evoke a light perception [22]. Since this threshold is outside the safe range for platinum electrodes, modifications of the electrodes became necessary and have been implemented successfully [23]. So far this group has supplied several retinitis pigmentosa patients with this type of implant and has been able to show that it may help to solve simple visual problems [24].

With a subretinal array of photodiodes, the optic picture is created using the refractive media of the eye. Epiretinal stimulations obtain the visual information from an additional optic system using a digital camera. The preparation of the visual signals recorded with the camera is challenging but at the same time represents a significant potential for epiretinal stimulation compared to the subretinal concept. As stated above, the information received by the ganglion cells of the normal retina no longer corresponds to a matrix of singular pixels. The situation becomes even more complex due to the fact that it is possibly not only the ganglion cells that are stimulated by an epiretinal stimulation. Evidence has emerged that the inner retinal layers, and the bipolar cells in particular, are excited by epiretinal stimulation. This could mean that the effect of stimulation is independent of sub- or epiretinal localization of the stimulator. Furthermore, it was recently shown that not only the somata, but also the axons of ganglion cells are activated by an epiretinal electrode [25]. 


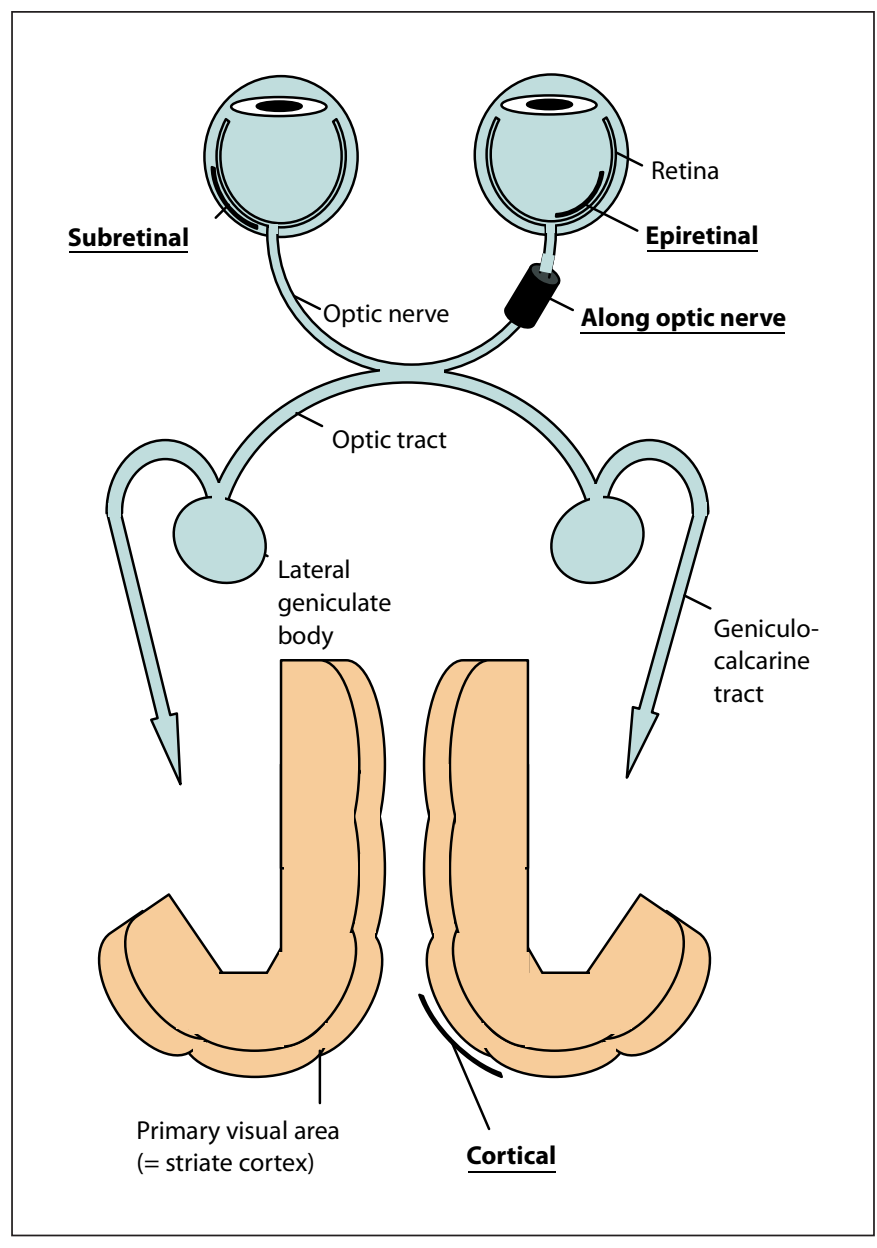

Fig. 1. This scheme highlights the potential sites for implantation of a visual prosthesis. Although at present the majority of research groups focus on epi- or subretinal implants, it has to be emphasized that electronic stimuli may be applied successfully to almost any part of the visual system.

A solution to these problems in the epiretinal approach might be the concept of a learning retina implant [26-28]. This concept is used by IMI Intelligent Medical Implants. Their system consists of an epiretinal stimulator that is fixed on the retina by one scleral tack and an electronic system connected to the stimulator. The implant is wirelessly controlled, inductively energized and receives its picture information wirelessly from a spectacle-mounted camera. However, the recorded pixel information is not transmitted 1:1 to the electrode matrix. It is modulated through a so-called retina encoder. In practice, a triangle, for example, is presented to the patient. The settings of the retina encoder are then modified until the patient perceives a triangle. This kind of calibration closes the gap of exact knowledge about retinal wiring. The parameterization of the retinal encoder occurs in an iterative process until the visual perception matches the desired picture information. Previous studies indicate that less than 100 iterations are necessary to adapt the system to the individual patient. The electrodes of the IMI system are modified so that a perception can be initiated already at very low charge densities, averaging below $1 \mathrm{mC} / \mathrm{cm}^{2}$ [29]. The IMI system is currently under clinical investigation in a multicenter trial. Previously no detectable damage to the retina could be found using optical coherence tomography and fluorescence angiography [30], while visual perceptions could be successfully evoked [31].

In the IMI system, the data transmission and power supply occur wirelessly for the first time. A part of the electronics is housed extraocularly under Tenon's capsule and is connected to the electrode stimulation array via a scleral tunnel [30]. The Epiret3 study group recently presented results of a completely intraocular implantable epiretinal stimulator. Transmission of data and energy occurs via an inductive link from an external unit. This includes a computer system, a transmitter and a transmitter coil, which is placed in front of the eye through a spectacle frame. The electronics of the receiver are implanted like an intraocular lens into the sulcus and have a wired connection to the epiretinal electrode array, which is anchored onto the retina by retinal tacks [32]. Besides a short duration of surgery, a lower complication rate compared to other epiretinal implants is now expected. However, long-term results of the Epiret3 implant are not yet available.

The longest follow-up data exist on the implant of the US company Second Sight Medical Products. The first long-term trials with a 16-electrode device (Argus-1) began in 2002 in 6 patients. In the meantime, there is already a second generation of this prosthesis, with 60 electrodes (Argus-2), in a phase II/III clinical trial, and 17 subjects have been implanted at 8 centers [33]. Further generations of 250 and over 1,000 electrodes are planned [34].

Table 1 gives an overview of current clinical trials involving epiretinal implants of the various working groups.

\section{Extraocular Visual Prostheses}

Extraocular visual prostheses play a minor role with regard to the whole range of research activities in developing a visual prosthesis, although this approach has a 
Table 1. Overview of recent clinical studies on epiretinal implants

\begin{tabular}{llll}
\hline & $\begin{array}{l}\text { IMI Intelligent Medical Implants } \\
\text { GmbH, Bonn, Germany }\end{array}$ & $\begin{array}{l}\text { Epiret GmbH, } \\
\text { Giessen, Germany }\end{array}$ & $\begin{array}{l}\text { Second Sight, } \\
\text { Sylmar, Calif., USA }\end{array}$ \\
\hline Number of electrodes & 49 & 25 & $16 / 60$ \\
\hline Maximum time retained within the eye & $>30$ months & 4 weeks & $>6$ years/>6 months \\
\hline Data transfer & wireless & wireless & wireless/wireless \\
\hline Signal receiver placement & epiretinal & lental & retroauricular/episcleral \\
\hline Specificities & freely programmable retina & $\begin{array}{l}\text { completely } \\
\text { implantable }\end{array}$ & $\begin{array}{l}\text { devices with 250+ and 1,000+ } \\
\text { electrodes in preparation/planning }\end{array}$ \\
\hline Homepage & www.imidevices.com & www.epiret.de & www.2-sight.com
\end{tabular}

long tradition. Both a direct stimulation of the optic nerve as well as a direct cortical stimulation are under investigation. The cortical electrical stimulation represents the oldest attempt to restore visual function through neurostimulation and is attributed to the French chemist and physicist Le Roy $[2,35]$. Since then, several variants of his experiments have been tried. One of the best known studies was conducted with an electrode array of 64 platinum electrodes, which were implanted in several patients at the end of the 1970s. In 1 patient, the array was kept in place for over 20 years. This person, who was blind after trauma, could perceive letters about $10 \mathrm{~cm}$ wide at a distance of $1.50 \mathrm{~m}$ [36]. A major problem lies in the control of light perception and the risk of triggering epileptic seizures by high stimulation currents [37]. Irrespective of this success, the cortical electrodes may lead to injury to the brain tissue, both during implantation and during stimulation. New concepts of cortical stimulation attempt to solve these problems and are being tested in animal experiments [38]. The main objectives of these trials are a reduction in stimulus thresholds and a reduction of brain trauma during implantation. Plans to test such systems in humans already exist [39].

Implants for the direct stimulation of the optic nerve are at an early stage of development [40]. In this approach the dura is removed from a region of the optic nerve, and a cuff with electrodes is placed around the nerve. There is a report by Veraart et al. [41] of a totally blind retinitis pigmentosa patient who could differentiate patterns under stimulation of the optic nerve after short training. Another report describes an improved transconjunctival implantation technique with a similar prosthesis [42].

Both the cortical and the optic nerve stimulation have the advantage of being completely independent from retinal function, and could be still applicable after severe ocular injury, at least in theory. On the other hand, corti- cal stimulation requires an immense surgical effort and poses a considerable risk to the patient. In direct stimulation of the optic nerve, it is difficult to adjust the position of electrodes to the visutope organization of the optic nerve. In addition, the optic nerve is difficult to access surgically.

\section{Future Perspectives}

More important than a decision for the best implantation site will be the understanding of the neurophysiological basis of signal processing in the visual system. This is required to adjust and optimize the design and function of a visual prosthesis. In theory reading should be possible with an array of only 60 electrodes [43]. However, due to a different visual perception through a prosthesis compared to normal vision, new methods must be developed that can describe even small subjective improvements noted by a patient, which are not yet detectable by our standard methods.

Another task is to deal with many technical challenges. More efficient wireless data and energy supply, combined with decreasing space requirement, longer durability and increased safety of the device are desirable. For a higher resolution, more, smaller and more densely mounted electrodes are needed.

All described methods have their own advantages and disadvantages, which are difficult to balance against each other from today's perspective. It is completely unclear which approach will lead to the best functional long-term results. The specific adjustment of a method to a particular disease will play a crucial role. Therefore, it may be assumed that there will not be one single universal solution. 


\section{References}

$>1$ Knauer C, Pfeiffer N: Blindness in Germany - today and in 2030. Ophthalmologe 2006; 103:735-741.

2 Le Roy C: Où l'on rend compte de quelques tentatives que l'on a faites pour guérir plusieurs maladies par l'électricité. Hist Acad R Sci (Paris), Mém Math Phys 1755;60:87-95.

$\checkmark 3$ Cohen ED: Prosthetic interfaces with the visual system: biological issues. J Neural Eng 2007;4:R14-R31.

$\checkmark 4$ Stone JL, Barlow WE, Humayun MS, de Juan E Jr, Milam AH: Morphometric analysis of macular photoreceptors and ganglion cells in retinas with retinitis pigmentosa. Arch Ophthalmol 1992;110:1634-1639.

$\checkmark 5$ Li ZY, Kljavin IJ, Milam AH: Rod photoreceptor neurite sprouting in retinitis pigmentosa. J Neurosci 1995;15:5429-5438.

6 Fariss RN, Li ZY, Milam AH: Abnormalities in rod photoreceptors, amacrine cells, and horizontal cells in human retinas with retinitis pigmentosa. Am J Ophthalmol 2000; 129:215-223.

$\checkmark 7$ Kim SY, Sadda S, Humayun MS, de Juan E Jr, Melia BM, Green WR: Morphometric analysis of the macula in eyes with geographic atrophy due to age-related macular degeneration. Retina 2002;22:464-470.

$\checkmark 8$ Chow AY, Chow VY: Subretinal electrical stimulation of the rabbit retina. Neurosci Lett 1997;225:13-16.

9 Chow AY, Pardue MT, Perlman JI, Ball SL, Chow VY, Hetling JR, Peyman GA, Liang C, Stubbs EB Jr, Peachey NS: Subretinal implantation of semiconductor-based photodiodes: durability of novel implant designs. J Rehabil Res Dev 2002;39:313-321.

-10 Chow AY, Chow VY, Packo KH, Pollack JS, Peyman GA, Schuchard R: The artificial silicon retina microchip for the treatment of vision loss from retinitis pigmentosa. Arch Ophthalmol 2004; 122:460-469.

$\checkmark 11$ Chow AY, Pollack JS, Packo KH, Schuchard RA: The artificial silicon retina microchip for the treatment of retinitis pigmentosa: 2 to 4 1/2 year update. Invest Ophthalmol Vis Sci 2005;46:E-abstract 1140.

12 Warren DJ, Normann RA: Visual neuroprostheses; in Finn WE, Lo Presti PG (eds): Handbook of Neuroprosthetic Methods. Boca Raton, CRC Press, 2003, pp 261-305.

-13 Pardue MT, Phillips MJ, Yin H, Sippy BD, Webb-Wood S, Chow AY, Ball SL: Neuroprotective effect of subretinal implants in the RCS rat. Invest Ophthalmol Vis Sci 2005;46: 674-682.

-14 Pardue MT, Phillips MJ, Yin H, Fernandes A, Cheng Y, Chow AY, Ball SL: Possible sources of neuroprotection following subretinal silicon chip implantation in RCS rats. J Neural Eng 2005;2:S39-S47.

15 Loudin J, Palanker D: Photovoltaic retinal prosthesis. Invest Ophthalmol Vis Sci 2008; 49:E-abstract 3014
16 Sachs HG, Schanze T, Wilms M, Rentzos A, Brunner U, Gekeler F, Hesse L: Subretinal implantation and testing of polyimide film electrodes in cats. Graefes Arch Clin Exp Ophthalmol 2005;243:464-468.

17 Schanze T, Sachs HG, Wiesenack C, Brunner $\mathrm{U}$, Sailer $\mathrm{H}$ : Implantation and testing of subretinal film electrodes in domestic pigs. Exp Eye Res 2006;82:332-340.

18 Zrenner E, Wilke R, Zabel T, Sachs H, BartzSchmidt K, Gekeler F, Wilhelm B, Greppmaier U, Stett A, Group SS: Psychometric analysis of visual sensations mediated by subretinal microelectrode arrays implanted into blind retinitis pigmentosa patients. Invest Ophthalmol Vis Sci 2007;48:E-abstract 659.

19 Wilke R, Porubska K, Benav H, Kusnyerik A, Bruckmann A, Koch J, Wilhelm B, Sachs H, Bartz-Schmidt KU, Zrenner E: Visual acuity determined by Landolt $\mathrm{C}$ test in a blind patient provided with a subretinal electronic implant. Invest Ophthalmol Vis Sci 2009; 50:E-abstract 4595.

20 Gerding $\mathrm{H}$ : A new approach towards a minimal invasive retina implant. J Neural Eng 2007;4:S30-S37.

21 Humayun M, Propst R, de Juan E Jr, McCormick K, Hickingbotham D: Bipolar surface electrical stimulation of the vertebrate retina. Arch Ophthalmol 1994;112:110-116.

22 Humayun MS, de Juan E Jr, Dagnelie G, Greenberg RJ, Propst RH, Phillips DH: Visual perception elicited by electrical stimulation of retina in blind humans. Arch Ophthalmol 1996;114:40-46.

23 Shah S, Hines A, Zhou D, Greenberg RJ, Humayun MS, Weiland JD: Electrical properties of retinal-electrode interface. J Neural Eng 2007;4:S24-S29.

24 Yanai D, Weiland JD, Mahadevappa M, Greenberg RJ, Fine I, Humayun MS: Visual performance using a retinal prosthesis in three subjects with retinitis pigmentosa. Am J Ophthalmol 2007;143:820-827.

25 Fried SI, Lasker AC, Eddington DK, Rizzo JF: Two different parts of the ganglion cell axon are activated by epi-retinal electrical stimulation. Invest Ophthalmol Vis Sci 2008;49:E-abstract 3034.

26 Eckmiller R, Neumann D, Baruth O: Tunable retina encoders for retina implants: why and how. J Neural Eng 2005;2:S91-S104.

27 Eckmiller RE, Borbe S: Selective tuning of temporal pattern presentation and electrode stimulation in a retina implant. Invest Ophthalmol Vis Sci 2008;49:E-abstract 5875

28 Eckmiller R: Learning retina implants with epiretinal contacts. Ophthalmic Res 1997;29: 281-289.

29 Feucht M, Laube T, Bornfeld N, Walter P, Velikay-Parel M, Hornig R, Richard G: Development of an epiretinal prosthesis for stimulation of the human retina. Ophthalmologe 2005;102:688-691.
30 Keserue M, Feucht M, Post N, Hornig R, Richard G: Clinical study on chronic electrical stimulation of the human retina with an epiretinal electrode array: fluorescein angiography and OCT findings. Invest Ophthalmol Vis Sci 2008;49:E-abstract 1785.

31 Richard G, Keserue M, Feucht M, Post N, Hornig R: Visual perception after longterm implantation of a retinal implant. Invest Ophthalmol Vis Sci 2008;49:E-abstract 1786.

32 Walter P, Mokwa W, Messner A: Epiret - the Epiret3 wireless intraocular retina implant system: design of the Epiret3 prospective clinical trial and overview. Invest Ophthalmol Vis Sci 2008;49:E-abstract 3023.

33 Humayun MS: Preliminary results from Argus II feasibility study: a 60 electrode epiretinal prosthesis. Invest Ophthalmol Vis Sci 2009;50:E-abstract 4744.

34 Chader GJ, Weiland J, Humayun MS: Artificial vision: needs, functioning, and testing of a retinal electronic prosthesis. Prog Brain Res 2009;175:317-332.

35 Uhlig CE, Taneri S, Benner FP, Gerding H: Electrical stimulation of the visual system: from empirical approach to visual prostheses. Ophthalmologe 2001;98:1089-1096.

36 Dobelle WH: Artificial vision for the blind by connecting a television camera to the visual cortex. ASAIO J 2000;46:3-9.

37 Javaheri M, Hahn DS, Lakhanpal RR, Weiland JD, Humayun MS: Retinal prostheses for the blind. Ann Acad Med Singapore 2006;35:137-144.

-38 Maynard EM, Nordhausen CT, Normann RA: The Utah intracortical electrode array: a recording structure for potential braincomputer interfaces. Electroencephalogr Clin Neurophysiol 1997;102:228-239.

39 Troyk PR, Bradley D, Bak M, Cogan S, Erickson R, Hu Z, Kufta C, McCreery D, Schmidt E, Sung S, Towle V: Intracortical visual prosthesis research - approach and progress. Conf Proc IEEE Eng Med Biol Soc 2005;7: 7376-7379.

40 Ren Q, Chai X, Wu K, Zhou C: Visual prosthesis based on optic nerve stimulation with penetrating electrode array; in Humayun MS (ed): Artificial Sight: Basic Research, Biomedical Engineering, and Clinical Advances. New York, Springer, 2007, pp 187-207.

41 Veraart C, Raftopoulos C, Mortimer JT, Delbeke J, Pins D, Michaux G, Vanlierde A, Parrini S, Wanet-Defalque MC: Visual sensations produced by optic nerve stimulation using an implanted self-sizing spiral cuff electrode. Brain Res 1998;813:181-186.

42 Brelen ME, De Potter P, Gersdorff M, Cosnard G, Veraart C, Delbeke J: Intraorbital implantation of a stimulating electrode for an optic nerve visual prosthesis: case report. J Neurosurg 2006;104:593-597.

43 Sommerhalder JR, Perez Fornos A, Safran $\mathrm{AB}$, Pelizzone $\mathrm{M}$ : Reading with a simulated 60 -channel retinal implant. Invest Ophthalmol Vis Sci 2008;49:E-abstract 3012. 